\title{
SENGKETA INDONESIA DAN TIMOR LESTE TERKAIT PERJANJIAN PERBATASAN MARITIM
}

\author{
Ida Kurnia $^{1}$, Alexander Sutomo ${ }^{2}$, Cliff Geraldio ${ }^{3}$ \\ ${ }^{1}$ Program Studi Ilmu Hukum, Universitas Tarumanagara \\ Email: idah@fh.untar.ac.id \\ ${ }^{2}$ Program Studi Ilmu Hukum, Universitas Tarumanagara \\ Email: alexander.205190033@ stu.untar.ac.id \\ ${ }^{3}$ Program Studi Ilmu Hukum, Universitas Tarumanagara \\ Email: cliff.205180164@stu.untar.ac.id
}

\begin{abstract}
The State of Timor Leste is an independent and sovereign country in the $21^{\text {st }}$ (twenty-first) century with its official name Democratica de Timor-Leste (RTL). Timor-Leste went through a long history to be able to stand alone as an independent country. Prior to the independence of Timor-Leste, it was called East Timor, which was a former colony of the Portuguese which later merged into the Unitary State of the Republic of Indonesia. It is recorded in history that integration was formalized on July 17, 1976. Then East Timor officially became the $27^{\text {th }}$ province of the Republic of Indonesia and became the youngest province at that time. In history, Timor-Leste was colonized by the Portuguese for 450 years, the Dutch for 3 years, and Indonesia for 24 years. Under the leadership of the United Nations through the United Nations Transitional Administration in East Timor.The establishment of Timor-Leste became a necessary new state on the border, especially with Indonesia. The issue of maritime boundaries between Indonesia and Timor-Leste has not yet been agreed. The method used is normative. Based on UNCLOS 1982, if maritime boundaries are included in the territory of state ownership, the principle used is the principle of equidistance. Second, there is no clear authority within the borders of Indonesia so that the current condition of Indonesia's borders, especially in terms of security, is not conducive. Third, based on Article 3 of UNCLOS, both countries have the right to the width of their territorial sea up to a limit of 12 miles from the baseline, if their territorial seas do not overlap.
\end{abstract}

Keywords: Maritime Boundary; Territorial Sea; Baseline.

\begin{abstract}
ABSTRAK
Negara Timor Leste merupakan negara yang merdeka dan berdaulat pada abad ke-21 (dua puluh satu) dengan nama resminya Democratica de Timor-Leste (RTL) merupakan suatu negara yang tidak terlalu besar yang terletak di Benua Australia dan timur Negara Indonesia. Timor-Leste melewati sejarah yang panjang hingga dapat berdiri sendiri sebagai suatu negara yang merdeka. Sebelum merdekanya Timor-Leste dahulunya disebut Timor-Timur yang merupakan wilayah bekas jajahan Bangsa Portugis yang kemudian bergabung dalam kesatuan Negara Republik Indonesia. Dalam sejarah tercatat bahwa integrasi telah diresmikan pada 17 Juli 1976. Selanjutnya, TimorTimur resmi menjadi provinsi ke-27 Negara Republik Indonesia dan menjadi provinsi paling muda di saat itu. Dalam sejarah Timor-Leste d jajah oleh Bangsa Portugis selama 450 tahun, Belanda 3 tahun, dan Indonesia selama 24 tahun. Dibawah pimpinan PBB melalui lembaga.United Nations Transitional Administration in East Timor.

Berdirinya Timor-Leste menjadi negara baru diperlukan batas wilayah khususnya dengan Indonesia. Pemasalahan batas maritim antara Indonesia dan Timor-Leste sampai saat ini belum ada kesepakatan. Adapun metode yang digunakan adalah normatif. Berdasarkan UNCLOS 1982 apabila batas maritim masuk ke dalam wilayah kedaulatan negara, maka prinsip yang dipergunakan adalah prinsip sama jarak (equidistance). Kedua, tidak adanya wewenang yang jelas dalam pengelolaan perbatasan Indonesia sehingga kondisi perbatasan Indonesia saat ini terutama dari sisi stabilitas keamanan belum kondusif. Ketiga, berdasarkan Pasal 3 UNCLOS kedua negara mempunyai hak atas lebar laut teritorialnya sampai batas 12 mil diukur dari garis pangkal, apabila tidak saling tumpang tindih wilayah laut teritorialnya.
\end{abstract}

Kata Kunci: Batas Maritim; Laut Teritorial; Garis Pangkal.

\section{PENDAHULUAN Latar Belakang}


Pada tanggal 7 Desember 1975, Indonesia mengadakan operasi yang dikenal sebagai Operasi Seroja, yang berencana untuk menyerang Timor Timur untuk memasukkan ke dalam domain Negara Kesatuan Republik Indonesia (NKRI). Kegiatan intrusi ini dilakukan Indonesia di bawah standar Soeharto setelah klaim dari Indonesia atas Timor Leste melalui Pengumuman Balibo. Dalam Kertas Kompas yang didistribusikan pada tanggal 29 Juni 1998, pada hari Minggu tanggal 28 Juni 1998 banyak massa Timor Timur memenuhi halaman Penginapan Mahkota, tempat para diplomat individu dari Kamar Asosiasi Eropa tinggal. Massa mendorong penugasan Pertemuan Uni Eropa untuk memegang mandat di Timor Timur segera. Massa menolak kemerdekaan teritorial untuk Timor Timur yang diakui oleh pemerintah Indonesia selama kerangka waktu perubahan, dan mengecam inklusi komunikasi luas Indonesia yang utama melihat kecenderungan Indonesia, kurang mengindir permintaan individu Timor Timur.

Pada masa pemerintahan Presiden BJ Habibie tepatnya 21 tahun sebelumnya, sejarah mencatat wilayah timur Indonesia, menjadi Timor Leste tertentu yang saat ini berganti nama menjadi Timor Leste yang terisolasi dari Indonesia.

Sejak Indonesia terisolasi dari Timor Leste, garis otoritas publik Republik Indonesia (RI) bersama dengan otoritas publik Timor Leste telah setuju untuk menentukan batas tanah dua bagian yang tidak tenang, khususnya di Noel Besi, Citrana dan Bidjael Sunan Oben. Menko Polhukam yang didampingi Menko Polhukam Retno Marsudi mengatakan, dengan terpenuhinya dua fragmen yang tidak tenang ini, cenderung diteruskan ke publik bahwa semua pengaturan batas darat antara kedua negara berada pada tingkat fundamental selesai dan akan dilanjutkan untuk perbatasan laut. Selain itu, pemahaman ini akan disimpulkan oleh Pertemuan Otoritas Senior yang akan diilustrasikan dalam Adendum No. 2 dari Pengaturan Batas 2005.

Kesalahan yang terjadi pada batas samudera Indonesia dan Timor Leste adalah bahwa tidak ada jaminan dan pedoman sehubungan dengan batas-batas regional, terutama di laut regional. Kedua, tidak ada ahli yang masuk akal dalam administrasi batas-batas Indonesia sehingga keadaan garis Indonesia saat ini, terutama sejauh ketergantungan keamanan, belum menguntungkan. Berdasarkan Pasal 3 UNCLOS 1982 menyatakan bahwa Indonesia dan Timor Leste berhak untuk menetapkan lebar laut regional mereka sejauh mungkin tidak melebihi 12 mil laut, diperkirakan dari pengukur yang ditentukan sesuai UNCLOS 1982.

Setelah penggabungan Timor Timur, Indonesia dan Australia tawar-menawar untuk menentukan jalur laut di Lubang Timor yang tidak tenang. Namun, ada perbedaan pada tingkat fundamental dalam menentukan batas batas laut antara kedua negara di mana Australia berpendapat bahwa di Timor Hole ada Saluran Timor sehingga sistem jaminan harus didasarkan pada pedoman kedalaman laut. Sementara itu, menurut Indonesia, Timor Hole adalah rak daratan sehingga jaminan delimitasi laut harus memanfaatkan aturan garis tengah sesuai UNCLOS 1982.

Adanya kontras perspektif dan mengingat bahwa jika tidak ada konsesi untuk batas samudera yang akan mempengaruhi aset minyak dan gas yang belum dijelajahi di Lubang Timor, kedua negara memilih untuk mendirikan Zona Partisipasi di Lubang Timor pada tahun 1989 disebut sebagai Pengaturan Lubang Timor sebagai jawaban untuk masalah kontras perspektif. Pengaturan ini mengisolasi Lubang Timor menjadi tiga zona dengan pembagian tingkat sesuai dengan yang dikukuhkan oleh kedua negara. Selain itu, pada tahun 1997, Indonesia dan Australia menyetujui Pengaturan Perth 1997 yang mengawasi delitimasi ZEE kedua negara di Laut Timor dan Laut Arafura.

Mengingat pemeriksaan ini ada dua penyelidikan mendasar setelah Timor Leste (Republik Timor Leste / RDTL) secara mandiri, khususnya:

Pertama-tama, belum ada jaminan dan pedoman mengenai batas regional, terutama di Oecusse, sebuah (wilayah) Timor Leste yang terletak di wilayah Indonesia di Timor Barat.

Kedua, tidak ada ahli yang masuk akal dalam administrasi garis Indonesia dengan tujuan bahwa keadaan garis Indonesia saat ini, terutama sejauh kesehatan keamanan, belum menguntungkan. 


\section{Rumusan Masalah}

1. Kendala yang mengakibatkan perbatasan maritim Indonesia dan Timor Leste belum terealisasikan?

2. Upaya apa yang harus seharusnya dapat ditempuh Indonesia untuk mengatasi agar dapat terealisasikannya perjanjian perbatasan maritim ?

\section{METODE PENELITIAN}

Penelitian ini menggunakan penelitian normatif. Jenis data yang digunakan adalah data sekunder, yang berupa peraturan-peraturan, baik yang sifatnya nasional maupun internasional. Disamping itu, digunakan juga buku/ artikel yang terkait dengan penelitian ini, termasuk kamus, media massa dan internet. Untuk melengkapi penelitian ini, maka akan digunakan data primer, namun penggunaan data primer sebatas untuk mendukung data sekunder.

Adapun yang utama dalam penelitian ini adalah dengan pendekatan undang-undang (statute approach) dilakukan dengan menelaah semua undang-undang dan regulasi yang bersangkut paut dengan isu hukum. Pendekatan undang-undang ini untuk menelaah adanya konsistensi dan kesesuaian substansi muatan undang-undang dengan mempelajari ontologis lahirnya undangundang, landasan filosofis undang-undang dan ratio legis dari ketentuan undang-undang. (Marzuki, 2007).

Menurut Soerjono Soekanto dan Sri Mamudji, di dalam penelitian hukum normatif, penelitian terhadap asas-asas hukum dilakukan terhadap kaidah-kaidah hukum, yang patokan-patokan berperilaku atau bersikap tidak pantas, Penelitian tersebut dapat dilakukan (terutama) terhadap bahan hukum primer dan bahan hukum sekunder, sepanjang bahan-bahan tadi mengandung kaidah hukum( Soekanto \& Mahmudji, 2010).

Dalam penelitian hukum normatif pengkajian terhadap kaidah hukum saja belum cukup, sehingga perlu kajian lebih lanjut pada aspek sistem hukumnya. Sistem merupakan tatanan atau kesatuan yang utuh yang terdiri dari bagian-bagian atau unsur-unsur yang saling berkaitan erat satu sama lain yaitu kaidah atau tentang pernyataan apa yang seharusnya, sehingga sistem hukum merupakan sistem normatif.(Mertokusumo, 2001).

Pendekatan penelitian menggunakan pendekatan sejarah hukum (Historical Approach) Pendekatan sejarah hukum dilakukan dalam kerangka pelacakan sejarah lembaga hukum dari waktu ke waktu. Pendekatan ini sangat membantu peneliti untuk memahami filosofi dari aturan hukum dari waktu ke waktu. Disamping itu, melalui pendekatan ini juga dapat diketahui perubahan dan perkembangan filosofi yang melandasi aturan hukum dimaksud.

Pendekatan konseptual menggunakan pendekatan wilayah negara yaitu Menurut Mochtar Kusumaatmadja konsep dasar dari ruang berlakunya kedaulatan sebagai kekuasaan tertinggi negara dibatasi oleh negara itu, sehingga negara memiliki kekuasaan tertinggi di dalam batas wilayahnya. (Kusumaatmadja \& Agoes, 2003).

\section{HASIL DAN PEMBAHASAN}

Perbatasan merupakan sebuah konsep yang sangat penting dalam hubungan antarnegara. Dari sudut pandang perdamaian, tanpa hubungan lintas batas yang saling dapat diterima, hubungan baik di antara negara yang bertetangga hampir tidak mungkin tercapai(Henrikson, 2000) Dalam pergantian peristiwa, baik sebelum penggabungan dan setelah rekonsiliasi Wilayah Timor Timur (saat ini Timor Leste), lautTimor dan laut Arafura mengalami unsur-unsur perbaikan yang berfluktuasi. Baik dalam jaminan batas-batas samudera maupun isu-isu yang ada di dua lautan tersebut.

Wilayah Timor Timur sebagai negara otonom dan berdaulat pada abad ke-21 dengan nama otoritasnya Republica Democratica de Timor Leste (RDTL) adalah sebuah negara kecil yang 
terletak di utara Daratan Australia dan Kondisi Timur Republik Indonesia. Timor Timur adalah negara otonom yang pernah penting bagi wilayah Indonesia yang dikenal sebagai Wilayah Timor Timur. Timor Timur sendiri memisahkan diri dari kekuasaan Indonesia pada tanggal 20 Mei 2002. Timor Timur memiliki sejarah panjang yang tersisa sebagai negara bebas. Provinsi Timor Timur dijajah oleh 3 (tiga) negara, khususnya:

Portugis untuk beberapa waktu, Jepang untuk waktu yang lama dan Indonesia untuk waktu yang cukup lama dan didorong oleh Negara-negara Berkumpul melalui sebuah yayasan yang disebut Organisasi Sementara Negara Bersatu di Timor Timur / UNTAET selama sekitar 2 tahun (24 Oktober 1999-20 Mei 2002).

Timor Leste adalah wilayah yang memiliki tempat dengan kelompok pulau Timor di Nusa Tenggara Timur. Wilayah ini pernah menjadi provinsi Portugis. Setelah Keputusan Kebebasan Dan Pengaturan Indonesia tentang wilayah Indonesia dengan Belanda, Timor Timur tidak masuk sebagai wilayah Republik Indonesia. Ini dengan alasan bahwa Timor Timur adalah provinsi Portugis.

Pada tanggal 30 Agustus 1999 yang dimulai dengan pemanasan suhu politik publik Indonesia ke fase penolakan Presiden Soeharto yang kemudian digantikan oleh BJ Habibie. Dalam waktu yang tidak begitu jauh melewati negara Timor Timur yang merupakan daerah ke-27 kemudian, pada saat itu, mengalami gangguan. Sebuah mandat diadakan di Timor Timur di bawah kesepakatan yang didukung negara-negara berkumpul. Dengan demikian, Timor Leste diisolasi dari NKRI.

Batas-batas suatu bangsa mengasumsikan bagian penting di mana pembentukan kembali adalah bagian antara bangsa-bangsa. Untuk memeriksa kekuatan regional suatu negara, diperlukan indikasi garis yang jelas dan sangat tahan lama. Karena, seandainya itu tidak dipisahkan dengan tanda yang masuk akal dan sangat tahan lama, itu pasti akan menyebabkan masalah dengan negara-negara yang bersebelahan yang dengan mudah berbaris.

Kejelasan mengenai garis batas baik di darat maupun di laut merupakan suatu yang penting untuk kedua negara yang berbatasan. Menurut Pasal 1 ayat (4) Undang-undang Nomor 43 Tahun 2008tentang Batas Wilayah Negara. Batas wilayah negara adalah garis batas yang merupakan pemisah kedaulatan suatu negara yang didasarkan atas hukum internasional. Ini berarti bahwa domain bangsa harus jelas, karena itu adalah tempat di mana negara mempertahankan kekuasaannya.

Sesuai pengaturan hukum internasional untuk situasi ini UNCLOS 1982 telah mengelola garis samudera negara-negara baik menghadapi dan menghubungkan diidentifikasi dengan batas-batas wilayah berdaulat dan lokal. Dalam pelaksanaannya, pengaturan pengaturan batas samudera yang mengidentifikasi dengan batas laut domain dan lingkup kedaulatan benar-benar diteruskan ke negara-negara penting untuk membuat kesepakatan. Namun, perlu diingat bahwa UNCLOS 1982 berubah menjadi prinsip payung. Pengaturan ini berisi jaminan poin-poin yang memfasilitasi batas-titik samudera kedua negara dan hak setiap bangsa untuk mempraktikkan kekuatannya dan menyelidiki kelimpahan normal yang terletak di dasar laut yang merupakan domain negara. Setelah koordinasi Timor Timur, Indonesia dan Australia tawar-menawar untuk menentukan jalur laut di Lubang Timor yang tidak tenang. Meskipun demikian, ada perbedaan pada tingkat dasar dalam menentukan batas batas laut antara kedua negara di mana Australia berpendapat bahwa di Timor Hole ada Timor Channel sehingga sistem jaminan harus didasarkan pada aturan kedalaman laut. Untuk sementara, sesuai Indonesia, Timor Hole adalah rak daratan sehingga jaminan delimasi laut harus memanfaatkan pedoman garis tengah sesuai UNCLOS 1982.

Karena ada kontras perspektif dan mengingat bahwa jika tidak ada konsesi terhadap batas laut yang akan mempengaruhi aset minyak dan gas yang belum dijelajahi di Laut Timor, kedua negara memilih untuk membangun Zona Partisipasi di Lubang Timor pada tahun 1989 yang 
disebut sebagai Pengaturan Lubang Timor sebagai jawaban untuk masalah kontras perspektif. Pemahaman ini membagi Lubang Timor menjadi tiga zona dengan pembagian tingkat sesuai yang setuju oleh kedua negara. Selain itu, pada tahun 1997, Indonesia dan Australia menyetujui Pengaturan Perth 1997 yang mengelola delimasi ZEE kedua negara di Laut Timor dan Laut Arafura.

Mengingat pemeriksaan ini ada dua penyelidikan utama setelah Timor Leste (Republik Timor Leste / RDTL) bebas, untuk lebih spesifik:

Pertama-tama, belum ada jaminan dan pedoman mengenai batas regional, terutama di Oecusse, sebuah (wilayah) Timor Leste yang terletak di wilayah Indonesia di Timor Barat.

Kedua, tidak ada ahli yang jelas dalam administrasi batas-batas Indonesia sehingga keadaan garis Indonesia saat ini, terutama sejauh ketergantungan keamanan, belum membantu.

Berdasarkan Pasal 59 UNCLOS 1982, tentang penyelesaian sengketa di ZEE, mewajibkan negara-negara untuk melakukan kesepakatan dengan cara yang adil dengan pertimbangan yang relevan. Indonesia dan Timor Leste hendaknya menetapkan garis equidistance sebagai batas wilayah laut setiap negara, atau menggunakan alternatif penyelesaian sengketa perbatasan laut kedua negara yang diarahkan pada penerapan prinsip uti possidetis juris dalam kepemilikan wilayah antara Republik Indonesia dengan RDTL (wilayah Kantung Oecusse).

Isu delimitasi batas laut RI - RDTL sebenarnya belum ada. Hal ini karena penetapan batas laut belum diperiksa, kedua negara telah sepakat untuk membicarakannya setelah pengesahan batas darat selesai. Isu-isu yang muncul saat ini pada umumnya akan datang dari perspektif keuangan.

Belum tentu batas wilayah laut setiap negara menyebabkan penangkapan ikan baik oleh pemancing Indonesia maupun pemancing RDTL masih sering memasuki ruang laut negara lapisan. Kekurangan Posko Lintas Garis Terkoordinasi antara Republik Indonesia (RI) - RDTL menyebabkan latihan persilangan melalui lautan penduduk RDTL dari Oeccusi ke Timor Leste atau sebaliknya secara alami melalui perairan Indonesia dan akan sulit dikenali. Kondisi demikian juga terjadi dalam bidang tukar-menukar, sehingga sering terjadi pertukaran yang melanggar hukum, seperti halnya peredaran gelap antara penduduk Indonesia dengan penduduk RDTL. Pos jalur saat ini antara RI - RDTL adalah untuk pos lintas jalur melalui darat.

Perlakuan terhadap perbatasan negara sejauh ini belum memiliki pilihan untuk berjalan ideal dan kurang tergabung dan masih ada perjuangan antara pertemuan yang berbeda (baik pada tingkat pesawat, sektoral, atau ke arah atas) yang tidak dapat di menjauh dari. Wawasan dengan masih kecurigaan bahwa perlakuan terhadap wilayah garis hanya memiliki tempat dengan otoritas publik (fokus) saja, harus diperbaiki, ditingkatkan dan dirubah, diidentifikasi dengan berjalannya waktu kemerdekaan teritorial, terlepas dari kenyataan bahwa wilayah garis adalah wilayah kunci publik. Nilai dasar dari garis tidak benar-benar diselesaikan antara lain oleh latihan yang terjadi di dalam lokal. Terlepas dari pergantian peristiwa provinsi, strategi diperlukan dan di antara Indonesia dan Timor Leste untuk mendapatkan kejernihan pada batas-batas regional. Otoritas publik Indonesia bergantung pada konstitusi dan undang-undang material yang berbeda dan selanjutnya otoritas publik menyusun strategi yang berbeda yang berubah menjadi referensi untuk pelaksanaan garis eksekutif. Indonesia melakukan strategi yang berbeda dalam menaklukkan bahaya garis antara Nusa Tenggara Timur dan Timor Leste. (Kusumaatmadja \& Agoes, 2003).

Selanjutnya, persyaratan untuk dasar Guard Tact Establishments, Joint Ministrial Commission (JMC), Joint Line Council (JBC) dan Specialized Sub-Panel on Line Outline and Guidelines (TSCBDR) ditegakkan oleh sepuluh kelompok Sub Advisory Khusus lainnya dalam mengawasi batas selama pengaturan konfirmasi batas antara kedua negara. (Qinvi, Sutisna , \& widodo, 2018) Berdirinya Dewan Pengawas Batas Bersama dalam pertemuan utama yang disampaikan oleh JBC Indonesia - Timor Leste meliputi: 
a) Setuju penunjukan Indonesia menolak proposisi Timor-Leste untuk membentuk subkomite khusus dalam perjalanan jalan ke dan dari Dili dan Oecussi yang akan berputar penuh dengan memanfaatkan transportasi darat;

b) Kedua belah pihak setuju untuk membentuk panel penutup garis, dewan pengawas mungkin bertemu kapan pun diperlukan.

c) Pihak yang berbeda setuju untuk membentuk subkomite khusus pada pedoman batas dan garis untuk berbicara tentang masalah yang mengidentifikasi dengan pinggiran kedua negara.

Timor Leste mengusulkan untuk membuat sistem jalur pertukaran laut untuk kapal konvensional untuk kesejahteraan transportasi dan pihak Indonesia menyebutkan periode kecantikan untuk memikirkan proposisi tersebut. (Sudika Mangku, 2017)

Selain itu, diplomasi sebagai strategi adalah pilihan yang benar dan sangat banyak dilakukan sehingga sangat berharga. Dalam mengatasi masalah garis ini, strategi dinamis oleh kedua negara mempertimbangkan periode waktu ukuran jaminan batas melalui pertemuan dan pengaturan di setiap pertemuan. Strategi yang diarahkan pemerintah Indonesia salah satunya adalah memimpin pertukaran dengan Timor Leste. Pertukaran diarahkan oleh otoritas publik Indonesia dalam menetapkan batas regional dengan Timor Leste melalui kebijaksanaan yang dipimpin oleh beberapa kantor penting untuk mendapatkan kejelasan tentang batas-batas regional perairan. Otoritas publik Indonesia bergantung pada konstitusi dan undang-undang terkait lainnya dan selanjutnya otoritas publik menyusun berbagai strategi yang berubah menjadi referensi untuk pelaksanaan garis dewan. Indonesia melakukan taktik yang berbeda dalam mengalahkan bahaya garis antara Nusa Tenggara Timur dan Timor Leste.

\section{KESIMPULAN DAN SARAN \\ Kesimpulan}

Belum jelasnya batas wilayah laut masing-masing negara menyebabkan penangkapan ikan baik oleh nelayan RI maupun nelayan RDTL masih sering memasuki wilayah laut negara yang berbatasan. Hal ini berdampak pada pengelolaan sumber daya hayati khususnya sumber daya ikan belum ada kejelasan, padahal dalam pengelolaan sumber daya ikan diperlukan perimbangan antara pemanfaatan dan pelestariannya, supaya sumber daya ikan dapat berkelanjutan. Selanjutnya tidak adanya Pos Perbatasan Laut Terpadu antara RI-RDTL yang menyebabkan aktivitas penyeberangan laut warga RDTL dari Oeccasi ke Timor Leste atau sebaliknya melalui perairan Indonesia dan akan sulit terdeteksi. Penanganan perbatasan negara selama ini belum dapat berjalan secara optimal dan kurang terintegrasi serta masih adanya konflik antar berbagai pihak (baik sektoral maupun vertikal) yang tidak dapat dihindari. Persepsi masih adanya anggapan bahwa penanganan kawasan perbatasan hanya milik pemerintah (pusat), perlu diluruskan, diperbaiki dan ditata ulang, terkait era otonomi daerah, padahal kawasan perbatasan merupakan kawasan strategis nasional.

\section{Saran}

Pemerintah Indonesia dalam hal ini secepatnya mengadakan perjanjian batas maritim dengan Timor Leste agar Indonesia dapat melindungi perairan Indonesia dari hal seperti penangkapan ikan oleh nelayan dari Timor Leste dan melindungi perbatasan Indonesia yang merupakan kawasan strategis nasional.

\section{Ucapan Terima Kasih (Acknowledgement)}

Sehubungan dengan telah dilaksanakannya kegiatan penelitian mengenai "Batas Maritim Indonesia dan Timor Leste", tim penelitian Fakultas Hukum Universitas Tarumanagara mengucapkan terima kasih kepada Lembaga Penelitian dan Pengabdian Kepada Masyarakat 
Universitas Tarumanagara yang telah memberi izin kepada tim peneliti Fakultas Hukum

Universitas Tarumanagara untuk mengadakan penepenelitia

\section{REFERENSI}

\section{Buku}

Atik,K. (2010).Penanganan Pengungsi di Indonesia (Tinjauan aspek Hukum Internasional dan nasional) . Penerbit Brilian Internasional, Surabaya.

Kusumaatmadja,M \& Agoes, ER. (2003). Pengantar Hukum Internasional. P.T. Alumni, Bandung.

Marzuki,PM . (2007). Penelitian Hukum .Kencana, Jakarta.

Soekanto,S \& Mahmudji,S.(2010). Penelitian Hukum Normatif: Suatu Tinjauan Singkat. Rajawali Pers, Jakarta.

Mertokusumo,S. (2001). Penemuan Hukum Sebuah Pengantar. Liberty, Yogyakarta.

Marnixon,WRC. (2006). Konsepsi Hukum dalam Pengaturan dan Pengelolaan Wilayah Perbatasan Antarnegara, PT. Alumni, Bandung.

\section{Jurnal}

Mangku,DGS.(2017). Implementasi Joint Border Committee (JBC) Untuk Penyelesaian Sengketa Perbatasan Darat antara Indonesia dan Timor Leste. Jurnal Yuridis,Edisi 1 Vol 5,43-66.

Henrikson, AK. (2000). "Facing across Borders: The Diplomacy of Bon Voisinage". International Political Science Review. No.21 Vol.2 , 121-147.

Dewi,RK. (2020). DIPLOMASI INDONESIA DALAM PENETAPAN BATAS PERAIRAN DENGANTIMOR LESTE, JOM FISIP, Edisi 1 Vol 7 Januari-Juni 2020. Qinvi,RF, Sutisna,S \& Widodo,P. (2018). DIPLOMASI PERTAHANAN DALAM PENYELESAIAN UNRESOLVED SEGMENT DI PERBATASAN DARAT INDONESIA - REPUBLIK DEMOKRATIK TIMOR LESTE (RDTL) (STUDI KASUS UNRESOLVED SEGMENT DILUMIL - MEMO) . Jurnal Diplomasi Pertahanan. Edisi 1 Vol 4.

\section{Internet}

http://e-journal.uajy.ac.id/11853/4/MIH017113.pdf

https://www.dpr.go.id/dokblog/dokumen/F_20150616_1906.pdf

http://news.unair.ac.id/2019/08/21/alternatif-penetapan-batas-wilayah-laut-nkri-dan-republikdemocratic-timor-leste/

https://setkab.go.id/segera-rundingkan-batas-maritim-ri-timor-leste-selesaikan-kesepakatanbatas-daratRibuan Massa Timtim Tuntut Referendum”, Kompas, Senin, 29 Juni 1998. https://wiken.grid.id/amp/392319251/seolah-membiarkan-lepasnya-timor-timur-dari-nkriternyata-inialasan-cerdas-bj-habibie-yang-tak-banyak-orang-tahu-demi-harga-diri-bangsa https://wiken.grid.id/amp/392319251/seolah-membiarkan-lepasnya-timor-timur-dari-nkriternyata-ini 
Seminar Nasional Hasil Penelitian dan Pengabdian Kepada Masyarakat 2021

Pengembangan Ekonomi Bangsa Melalui Inovasi Digital Hasil Penelitian dan

Pengabdian Kepada Masyarakat

Jakarta, 21 Oktober 2021

(halaman kosong) 